A nim. Behav., 1995, 49, 333-345

\title{
Short-term costs and correlates of play in cheetahs
}

\author{
T. M. CARO \\ Department of W ildlife, Fish and Conservation Biology and C enter for Population Biology, \\ U niversity of California, Davis, CA 95616, U.S.A. \\ and \\ Serengeti W ildlife Research Institute, P.0. Box 661, A rusha, Tanzania
}

( Received 2 J une 1993; initial acceptance 16 J uly 1993;

final acceptance 19 D ecember 1993; M S. number: ${ }^{46722)}$

\begin{abstract}
A bstract. Costs and benefits of play were investigated by observing cheetah, A cinonyx jubatus, cubs in the wild. Cubs played either after resting or nursing, or while the family was moving; cubs were never injured during $2600 \mathrm{~h}$ of observation, and did not become separated from their mother during play; and mothers showed few signs of unease while cubs played. It is argued that energetic and indirect costs of play were insubstantial. Taking all these potential costs together, overall costs of play appeared low. Very young cubs showed high rates of locomotor play suggesting that play may have immediate rather than delayed benefits, possibly aiding cubs in escaping predation. Components of non-contact social play may be functionally or causally related to approaching prey, whereas components of object and contact play may be related to contacting prey. Litter-mates that stalked and crouched at other family members more frequently during play also stalked and crouched at prey more often, and those showing more frequent object play and contact social play showed higher rates of contacting live prey released for them by their mothers. Distances that cubs chased each other and their success in catching each other during play chases increased with age but the ability of cubs to remain concealed during play stalks and crouches did not improve, implying that only certain aspects of play might be suitable for rehearsing predatory skills.
\end{abstract}

One of the central issues in the study of play is to determine its function because its adaptive significance is poorly understood despite years of research (reviewed in Smith 1982; Caro 1988). Current functional theories fall into four major categories: (1) those that suggest that play serves to develop adult predatory and fighting skills, as well as fostering physical strength and endurance; (2) those that regard play as a means of social bonding and as a way to acquire skills for communication; (3) those that see play as a way of increasing individuals' cognitive and innovative abilities; and (4) those that view play as a means of energy regulation (Bekoff \& Byers 1981; Barber 1991).

$M$ ost theories consider that the benefits of play are delayed until adulthood (Muller-Schwarze 1984) but this view stems from observations that there are no obvious benefits that young mammals derive from play. $Y$ et benefits would have greater selective advantage if they acted earlier rather than later in ontogeny because of the cumulative effects of mortality (M artin \& Caro 1985). M oreover, limited evidence from human and non-human primates indicates play may promote problemsolving abilities and skill acquisition in the short term (human studies reviewed in Smith \& Simon 1984; common marmosets, Callithrix jacchus; Chalmers \& Locke-H aydon 1984), whereas evidence of long-term effects are almost non-existent.

In this paper, I use naturalistic observations of cheetah, A cinonyx jubatus, cubs to investigate the short-term benefits of play using correlational approaches and arguments from design. I focus on the first, motor-training hypothesis because current evidence, such as it is, supports this more than other adaptive hypotheses for play (Smith 1982). If play serves as practice for hunting, one might expect particular skills exhibited in play to improve with age, because this would provide increasingly effective rehearsal for hunting skills. To explore such changes, aspects of play are examined in detail focusing on cubs' ability to remain concealed, distances covered in play bouts, and cubs' success in catching up and contacting play partners. 
First, however, short-term costs of play are addressed. A few studies (e.g. M artin 1984; M iller $\&$ Byers 1991) have attempted to assess the costs of play to gauge the magnitude of its potential benefits but have usually considered only one or two types of cost. If only time and energy costs are examined, and are found to be low, while survivorship costs are high, interpretations based on the low costs of play will be problematic. $\mathrm{H}$ ere I attempt to assess all the costs of play in one study to provide preliminary data on the overall costs of play in one species.

Carnivores are thought to play more extensively than individuals in other orders and, perhaps related to this, there is a large body of literature on carnivore play albeit of a qualitative nature (F agen 1981; Bekoff 1989). Cheetahs have been noted for their vigorous play (Adamson 1969) which consists of crouching, stalking, pouncing and chasing (Schaller 1972) and cheetah cubs knock each other over during play with the typical paw slap that is later used to knock prey off balance (Prater 1935). Popular literature has also drawn attention to cheetahs' rapid and abundant play (F rame \& F rame 1980; Estes 1991), making the species a promising candidate for investigating the function of play.

\section{METHODS}

\section{Study Site and $\mathbf{O}$ bservation Schedule}

The study was conducted on the central plains of the Serengeti N ational Park, Tanzania between $M$ arch 1980 and D ecember 1983 (for details see Caro 1994). I made observations on individually recognized mothers and cubs from a vehicle during daylight hours. I usually made observations at a distance of $0-150 \mathrm{~m}$ by eye or with the aid of $8 \times 40$ binoculars. I watched families all day for $1-7$ consecutive days; $66.7 \%$ of these watches were 4 or more days in length.

\section{A ge of Cubs}

I observed litters that had emerged from the lair at nine different ages at approximately 1-month intervals. Because the exact birth dates of most cubs were unknown, I estimated ages of cubs accompanying their mother based on comparison of body sizes with cubs of known age (following
L aurenson 1993; G . Frame \& L. F rame, personal communication). Cubs with black manes and less than one-quarter of their mother's height at the shoulder were estimated as 2 months old; those with black manes but less than a third of their mother's height as 3 months; those that were more than a third of their mother's height with fluffy shoulders as 4 months; those just under half their mother's height as 5 months; and those just above half their mother's height as 6 months. Cubs older than this showed sexual dimorphism. I estimated the age of sons that were two-thirds and daughters that were five-eighths of their mother's height to be 7 months old. If sons were threequarters or daughters two-thirds of their mother's height, I scored them as 8.5 months old; if sons were seven-eighths or daughters three-quarters of their mother's height, I scored these as 10.5 months old. If sons were as large or larger, or daughters were seven-eighths or as large as their mothers, I estimated their age to be $\mathbf{1 2 . 5}$ months or older. F emale cubs in this last age category before independence could be distinguished from their mothers by their slighter build, fluffier manes and round cub-like faces. A geing was facilitated if the family contained both sons and daughters but these criteria were also used in the seven families in which only a single offspring was present.

In some analyses, I combined the nine age classes into three larger categories: cubs 2-4 months old were termed young; 5-7 months old, middle-aged; and dependent cubs 8.5 months or older were called old cubs.

I conducted behavioural observations without radio telemetry, and it proved impossible to relocate a family at will a month after a period of observation. Instead, I watched a minimum of four different families at each age enabling ontogenetic changes in behaviour to be monitored using a minimum sample size. I observed only litters of up to four cubs because I could not record accurately the behaviour of more than five cheetahs simultaneously, especially at kills. In any case, litter sizes of more than four were very rare in older age categories. In general, rates of play differed little according to litter size.

\section{B elly Size E stimates}

At the start of each day's observation, I made an estimate of each family member's level of hunger by scoring each member's belly size on a 
scale from 1 (very emaciated) to 14 (fully extended) when they would voluntarily leave a kill if there was still meat on it. Belly size estimates have been used reliably by other researchers working on cheetahs (F rame \& F rame 1981) and lions, Panthera leo (Bertram 1978; Packer 1986) and experienced observers of cheetahs almost always scored individuals identically (see Caro 1987a for details of inter-observer reliability).

\section{Behavioural Definitions}

Cheetah cubs interacted with each other, with their mother and with objects, and often ran around by themselves in a vigorous, active way which apparently served no immediate purpose. Interactions were physical, or involved chasing or seemingly, hunting, or fleeing from family members. Because the cubs' activity was apparently non-functional and was often exaggerated and repeated, it conformed to classical definitions of play (Fagen 1981; M artin \& Caro 1985). To record play, I observed cubs from the time I first found them until 0930 hours when they began to rest, and from 1700 hours until dusk. During the first minute, I focused attention on one cub, then switched to the next at the onset of the second minute, and so on, eventually returning to the original cub. I recorded four main categories of play and one category of exploration (Table I). I derived rates of play for each cub by summing the total number of times it performed all behaviour patterns constituting a particular type of play (Table I) and dividing it by the number of minutes that cub was active (i.e. walked, ran or played; see Bekoff \& Byers 1992); I then calculated an average for all the cubs in the litter (A bbey \& Howard 1973; M artin \& Bateson 1986).

I also estimated the distance in metres that cubs rushed around, or chased each other during play. A Ithough distances were estimated by eye, I kept my standards high by (1) estimating distances between objects back at my base in Serengeti, then measuring them and mentally noting the discrepancy and (2) by placing a line of cans at 10-m distances away from my porch that I could view repeatedly during leisure hours. In addition, I scored the percentage of chases that ended with the conspecific actually being contacted, and whether cubs were seen by their targets while they were stalking or crouching at each other or their mother during play. It was easy to see when cubs
T able I. B ehaviour patterns comprising different types of play and exploration of cheetah cubs in this study

\begin{tabular}{clc}
\hline \multicolumn{1}{c}{ Type of play } & Behaviour patterns & R ecipient \\
\hline L ocomotor play & $\begin{array}{l}\text { Bounding gait } \\
\text { R ushing around }\end{array}$ & N o recipient \\
Contact social play & $\begin{array}{l}\text { Patting } \\
\text { Biting } \\
\text { K icking }\end{array}$ & $\begin{array}{c}\text { A ny family } \\
\text { member }\end{array}$ \\
& G rasping & \\
Object play & Patting & Object \\
& Biting & \\
& K icking & \\
N on-contact & Carrying & A ny family \\
social play & Stalking* & member \\
& Crouching* & \\
& Chasing & \\
Exploration & Fleeing & \\
& R earing up & Object \\
\hline
\end{tabular}

Definitions: bounding gait: slow run with stiff legs causing a rocking motion; rushing around: short sprint often including turns; pat: slap or touch with forepaw; bite: close jaws on animal or object; kick: strike with hindfeet; grasp: hold with forepaws or forelegs; carry: move with object in mouth; stalk: slow approach with body held low; crouch: stationary posture with body low and belly often on ground; chase: run after another animal; flee: run away from another animal; rear up: forelegs off the ground; sniff: place nose close to object. $*$ Crouches and stalks that continued from one cub's focal minute to the next were scored just once.

were discovered as their target would stare at them intently. Cub activity was fast but the sequential focal-animal recording technique enabled me to concentrate on one subject without being distracted by the activities of others.

At the start of each minute, I estimated the distance of the focal cub from its mother. To determine whether play took cubs far from their mother, I divided the summed distances from the mother by the number of minutes in which cubs played, or were active but did not play. I then took an average over all the morning watches for each type of measure. I also noted the mother's posture at the start of each minute. These were lying alert: lying with flank and hindquarters on the ground but forelegs tucked under the body; sitting up: sitting on backlegs with forelegs vertically supporting the body; crouching and standing. The former two measures represented unease on the part of the mother (Caro 1987a). The distance from the mother and her posture at the start of a minute was a reasonable reflection of 
the play situation because the length of many play bouts were long and had often started before the minute under consideration. Finally, I recorded each instance of cubs climbing trees (i.e. having all feet off the ground) throughout the day.

I recorded the rate at which cubs exhibited bouts of stalking and crouching during hunts of appropriate and inappropriate prey (see Caro 1994) and compared these with rates of the same behaviour patterns seen in play. Cubs were poor at approaching prey undetected, however, and hence had minimal opportunities to interact physically with prey. Thus, I could not determine whether their ability to contact prey improved in the context of hunts. N evertheless, there were two situations in which I witnessed cubs contacting prey: when their mother released live prey for them (Caro \& Hauser 1992), and when she presented them with dead prey prior to the family feeding. A ccordingly, I recorded the frequency of contact (i.e. biting, kicking, grasping and pawing) with live and dead prey separately for each cub and divided the first value by the time between release and death, and the second value by the time between death and being eaten. I could then compare the frequency of play seen on a daily basis with rates of contact behaviour in situations when live and dead prey were offered and thus determine whether differences in play were reflected in differences in hunting skills.

To monitor activity budgets throughout the day, I noted the following activities of each cheetah every 15 min since subjects rarely changed activities more often than this: resting: lying with flank and hindquarters touching the ground; observing: sitting on backlegs with forelegs vertically supporting the body, or standing; moving: walking or running; eating: chewing meat or bones; and playing as defined above. Hunting started when the subject either crouched at, stalked, trotted towards, rushed at or chased prey. I also recorded churring, a single soft chirrup or series of chirrups that mothers used to call their cubs to them.

\section{A nalyses}

In general, non-parametric statistics were used in analysis as most data could not be normalized using standard transformations. For each behaviour pattern listed in Table I, I compared watches lasting a single day with longer watches using
M ann-W hitney U-tests or t-tests to determine whether short watches were unrepresentative of cheetahs' behaviour. If significant differences were found $(P<0 \cdot 1)$, I dropped single-day watches from subsequent analyses of that measure.

Families were observed on 54 occasions, but some litters were observed at more than one age (27 once; four twice; five, three times; and one, four times). Also some mothers were observed more than once either with the same or different litters (22 once; five twice; two, three times; and four, four times). Previous analyses (Caro 1987a, 1990) have examined whether individual differences between mothers were an important source of variation in maternal behaviour but there were few measures in which significant effects were found. This held particularly where sample sizes (and hence replicates) were reduced after dropping single-day watches. F urthermore, in many nonparametric tests it was very difficut to control for any maternal effects when examining how cub age influenced behaviour because of the uneven number of replicate litters or mothers. F or all three reasons, individual differences between mothers or litters were not investigated here.

\section{RESULT S}

\section{The D evelopment of Play}

\section{Time cubs devoted to play}

Cheetah cubs that had recently emerged from their lair played for an average of 3.4\% of the day until they became independent. Two-month-old cubs played for a greater proportion of the day than any other age group (Fig. 1), an average of $7.6 \%$ of the day, or $0.9 \mathrm{~h}$ in every $12 \mathrm{~h}$. One litter played for over $15 \%$ of the day. The percentage of time cubs spent playing remained high, at an average of over $5 \%$ until they were 4 months old, and then steadily declined with age (Spearman correlation coefficient, $r_{S}=-0.777, N=41$ litters watched for 2 or more days, $P<0.0001$ ). Nevertheless, cubs at 8 months of age still played for $2.5 \%$ of the time, and it was not until they were 10 months old that they played for less than $1 \%$ of the day.

Time course of different types of play

The four categories of play all showed a decline in frequency during development, in contrast to 


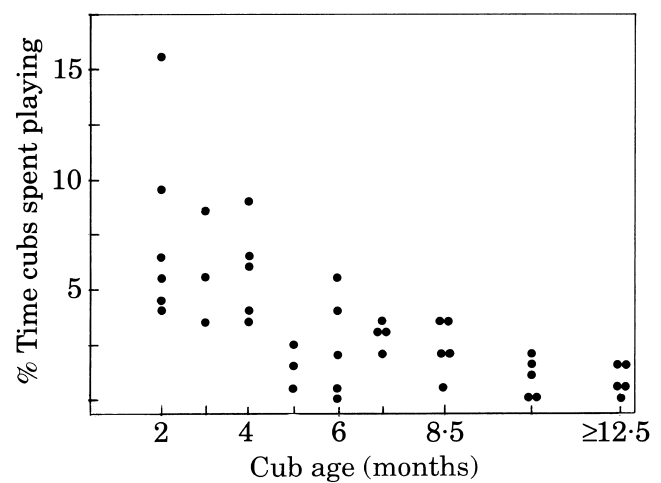

Figure 1. Percentage of $15-\mathrm{min}$ scans that cubs in 41 litters (watched for 2 or more days) were seen playing plotted against cub age; each point represents an average for all cubs in a litter.

exploratory behaviour, which rose steadily with age (Fig. 2; $\mathrm{N}=43$ litters: locomotor play: $r_{S}=-0.802, \quad P<0.001 ;$ contact social play: $r_{S}=-0.738, P<0.001 ;$ object play: $r_{s}=-0.467$, $P<0.001$; non-contact social play: $r_{s}=-0.660$, $P<0.001$; exploration: $r_{s}=0.320, \quad P=0.018$ ). Whereas locomotor play was at its highest point at 2 months of age and declined rapidly from then on, the other three play categories rose between 2 and 3 months of age. The frequency of object play peaked slightly later than contact or non-contact social play, and as a consequence there was no significant difference between young and middleaged litters in object play as there was for other play categories ( $\mathrm{M}$ ann-W hitney $\mathrm{U}$-tests comparing the frequencies of play behaviour patterns/ active $\mathrm{min} /$ cub for young cubs, $\mathrm{N}=17$ litters, and middle-aged cubs, $\mathrm{N}=12$ litters: locomotor play: $\bar{X}_{S}=0.27,0.08$, respectively, $U=29, \mathrm{P}<0.002$; contact social play: $X_{S}=1 \cdot 25,0.63, U=36, P<0.002$; non-contact social play: $\bar{X} s=0.37,0.19, U=42.5$, $\mathrm{P}<0.02$; object play: $\bar{X} s=0.25, \quad 0.16, \quad U=82$, $P>0 \cdot 1)$.

\section{Costs of Play}

Opportunity costs

Cubs spent approximately $80 \%$ of the time playing, resting, nursing and moving and this percentage was quite constant across different ages. Cubs spent the other $20 \%$ of the day observing, eating and hunting ( $\mathrm{Fig} .3$ ). A though time spent resting in the first 3 months after emergence

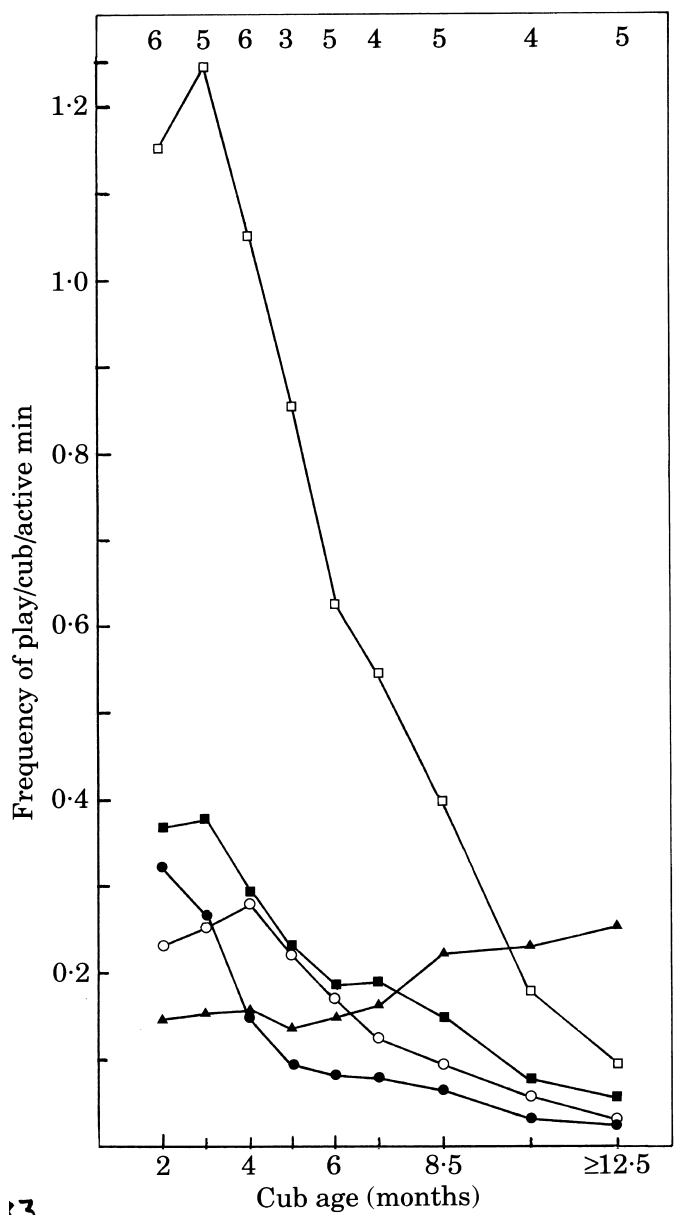

Figure 2. R unning mean values of non-contact social play ( $\mathbf{\square})$, contact social play $(\square)$, locomotor play $(\bullet)$, object play ( $\bigcirc)$, and exploratory behaviour ( $\boldsymbol{\Delta}$ ) per cub per active minute during morning watches plotted against cub age. Running means were used to reduce variability caused by small sample sizes at some ages and were calculated by taking an average of the scores for a given age and the two ages on either side of it. $\mathrm{N}$ umbers of litters are shown at the top.

was lower than at other ages, this loss could be attributed to nursing as much as to playing.

\section{I njury costs}

During $2600 \mathrm{~h}$ of observation, cubs were never permanently injured as a result of playing on the ground. Very occasionally a cub would place its foot in a small hole during a play chase, and limp briefly for perhaps $10 \mathrm{~min}$. In contrast, adults 


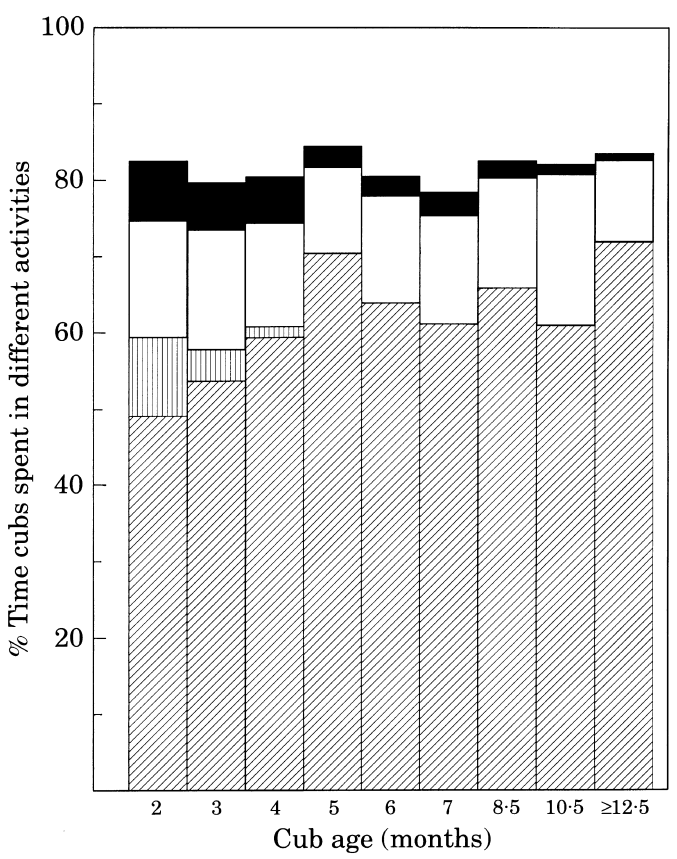

Figure 3. Percentage of 15 -min scans in which cubs in 41 litters (watched for 2 or more days) were seen to rest $(\square)$, nurse $(\mathbb{\square})$ ), move $(\square)$ and play ( $\square$ ) plotted against cub age.

were observed hobbling more severely for periods lasting up to 3 days probably as a result of injuries sustained during high-speed hunting chases (personal observation). Injuries suffered in play therefore appeared much less important than those sustained by adults in non-play activities.

Cubs also played by jumping up on to the limbs of fallen trees to look around and to sniff, bite and pat the bough itself. Furthermore, young cubs tried to ascend the vertical trunk of living trees in the same way as leopards, P anthera pardus. The average rate of tree climbing was $0 \cdot 06 / \mathrm{cub} / \mathrm{h}$ over the course of development and did not decline with age $\left(r_{s}=-0.0142, N=41\right.$ litters, $\left.P>0.4\right)$. Ascending trees was potentially dangerous because cubs fell an average of $18 \cdot 1 \%$ of the time, from as high as $5 \mathrm{~m}$; however, I never saw a cub injured through falling.

\section{R isks of separation}

Young cubs were found significantly further away from their mothers at the start of minutes in which one or more play bouts occurred than at the start of minutes in which they were active but did not play ( $\overline{X s}=5.1,4.2 \mathrm{~m}$ for play versus active minutes respectively, Wilcoxon test, $z=2 \cdot 114$, $N=19$ litters, $P=0.025)$. $M$ others, however, were so close in both cases that it seemed unlikely that play could affect their ability to defend offspring against predators. In older, less vulnerable age groups, the estimated distance from the mother did not differ significantly between playing and active cubs (middle-aged cubs: $\bar{X} s=9 \cdot 3,9.4 \mathrm{~m}$, respectively, $z=-0.311, N=12$ litters, $P>0.7$; old cubs: $\overline{X s}=12.9,16.9 \mathrm{~m}, \mathrm{z}=-0.075, \mathrm{~N}=20$ litters, $P>0.9$ ). In summary, play did not result in cubs straying far from their mother.

\section{$M$ aternal responses to potential predation risk}

Locomotor play and non-contact social play were the most visually conspicuous forms of play. When viewed from afar, they often alerted me to the fact that a female had offspring and might therefore have increased predation risk from lions and spotted hyaenas, Crocuta crocuta, which are known to prey on cheetah cubs (Caro 1987a).

A lthough I had no direct measures of predation risk, I used mothers' responses to play as an indirect measure. Mothers did not beckon their cubs to return to them by churring more often in those minutes when cubs were playing than when they were not. In only one out of 31 litters in which the mother churred at least once, did churring occur significantly more often during play minutes than during non-play.

$M$ easures of maternal unease were no greater at the start of minutes that included play than at the start of those in which cubs were simply active $(\mathrm{N}=51$ litters averaged over morning watches, mothers lying alert: $\bar{X} s=16 \cdot 5 \%, 15 \cdot 5 \%$, W ilcoxon test, $z=0.169, P>0.8$; mothers sitting up: $18.2 \%$, $19.0 \%, z=-0.138, P>0.9)$, nor did I notice increased vigilance on the part of mothers when their cubs played, although this was not scored systematically. While mothers with young cubs spent a greater proportion of time crouching and standing at the onset of minutes containing play compared with those when cubs were simply active (mothers crouching: $\bar{X} s=2 \cdot 6 \%, 0.6 \%$, Wilcoxon test, $z=2 \cdot 429, P=0.015$; mothers standing: $11 \cdot 6 \%, 8 \cdot 1 \%, z=2 \cdot 052, P=0.040$ ) these usually represented mothers about to join in on their cubs' play. In summary, play did not provoke appreciable maternal unease, suggesting that cubs did not put themselves at increased risk to predators during play. 


\section{Energy costs}

Energetic costs of play could not be assessed in this study. Nevertheless, the percentage of time that litters played was strongly correlated with the percentage of time they spent eating (partial correlation coefficient on ranked data controlling for cub age, $r=0.570, \quad N=48$ litters, $P<0.001$ ) although these activities were very rarely juxtaposed in time. Correlations between mean belly size of litter-mates and proportion of minutes in which cubs played each morning were not significant, however, based on the 21 litters in which cubs were watched on 6 or 7 mornings. This was because cubs with large bellies, of size 8 or above, played comparatively little, possibly because they were uncomfortable running or rolling around when their bellies were stretched. Thus, better nourished offspring played more but only after the effects of a big meal had worn off.

\section{A ssociations between Play and Predatory Behaviour}

In those litters in which cubs exhibited higher rates of stalking and crouching at other family members during non-contact social play, cubs respectively stalked and crouched at prey more often (partial correlation coefficient on ranked data controlling for cub age, stalk: $r=0.240$, $N=51$ litters, $P=0.044$; crouch: $r=0.237, N=51$ litters, $P=0.044)$. There was, however, no significant association between rushing during locomotor play, and chasing during non-contact social play, and the same behaviour patterns while hunting (rush: $r=0.050, N=37$ litters, $P>0.3$; chase: $r=0 \cdot 127, \quad N=51$ litters, $P>0 \cdot 1$ ). Litters that showed higher total rates of object play, and contact social play, exhibited higher total rates of patting, biting and grasping live prey released for them by their mothers (Table II). In contrast, rates of locomotor and non-contact social play in cheetahs were not significantly correlated with rates of contact of live prey. $\mathrm{N}$ o category of play was significantly correlated with contact rates on dead prey prior to feeding (Table II).

\section{A ge C hanges in Subtle A spects of Social P lay}

Remaining concealed during play and hunting

It was difficult for cubs to remain concealed from each other while playing because they stayed
T able II. Pearson correlation coefficients on ranked data comparing rates of different categories of play with rates of contact on live and dead prey (averaged across prey for each litter), controlling for cub age

\begin{tabular}{lcc}
\hline \multicolumn{1}{c}{ Type of play } & $\begin{array}{c}\text { Live prey } \\
\text { released } \\
(\mathrm{N}=15)\end{array}$ & $\begin{array}{c}\text { Dead prey } \\
\text { presented } \\
(\mathrm{N}=19)\end{array}$ \\
\hline Locomotor play & 0.299 & 0.084 \\
Object play & $\mathrm{P}>0.1$ & $\mathrm{P}>0.4$ \\
Contact social play & 0.631 & -0.022 \\
& $\mathrm{P}=0.003$ & $\mathrm{P}>0.4$ \\
N on-contact social play & 0.566 & 0.088 \\
& $\mathrm{P}=0.009$ & $\mathrm{P}>0.3$ \\
& $\mathrm{P}>0.293$ & $\mathrm{P}>0.192$ \\
& & \\
\hline
\end{tabular}

$\mathrm{N}$ refers to the number of litters.

in close proximity. Only an average of $24.4 \%$ of play stalks ( $\mathrm{SE}=5 \cdot 3, \mathrm{~N}=23$ litters) and $20 \cdot 3 \%$ of play crouches ( $\mathrm{SE}=4 \cdot 1, \mathrm{~N}=33$ litters) remained undiscovered by target family members and these proportions did not alter with cub age (stalk: $r_{S}=0.086, P>0.3$; crouch: $\left.r_{S}=0.024, P>0.4\right)$. In contrast, an average ( $\pm \mathrm{SE}$ ) of $60 \cdot 8 \pm 11 \cdot 8 \%$ of crouches at prey ( $\mathrm{N}=14$ litters over 4 months of age, as this was the first time cubs crouched in hunts, and excluding litters in which only one crouch occurred) remained undiscovered as prey was further away than family members, and cubs showed an age-related improvement in keeping concealed while crouching at prey $\left(r_{S}=0.447\right.$, $P=0.055)$. Stalking prey, however, still appeared difficult because a high proportion of stalks were detected by prey $(67 \cdot 1 \%, \mathrm{SE}=14 \cdot 6, \mathrm{~N}=22$ litters excluding those in which only one stalk occurred) and cubs did not get appreciably better at stalking prey undetected $\left(r_{S}=0.151, P>0.2\right)$.

\section{Distances covered during play and hunting}

The estimated distance over which cubs chased each other $(\bar{X}=7.8 \mathrm{~m}, \mathrm{SE}=0.5, \quad \mathrm{~N}=44$ litters excluding those in which only one chase occurred) increased with age $\left(r_{s}=0.574, P<0.001\right)$. It seems unlikely that greater distances were simply a consequence of older cubs' greater stamina because estimated distances covered during bouts of rushing around $(\bar{X}=6.3 \mathrm{~m}, \mathrm{SE}=0.5, \mathrm{~N}=29$ litters excluding those in which only one rush occurred) did not increase during ontogeny $\left(r_{s}=-0.006\right.$, $P>0.4$ ). Increasing distances covered in play 


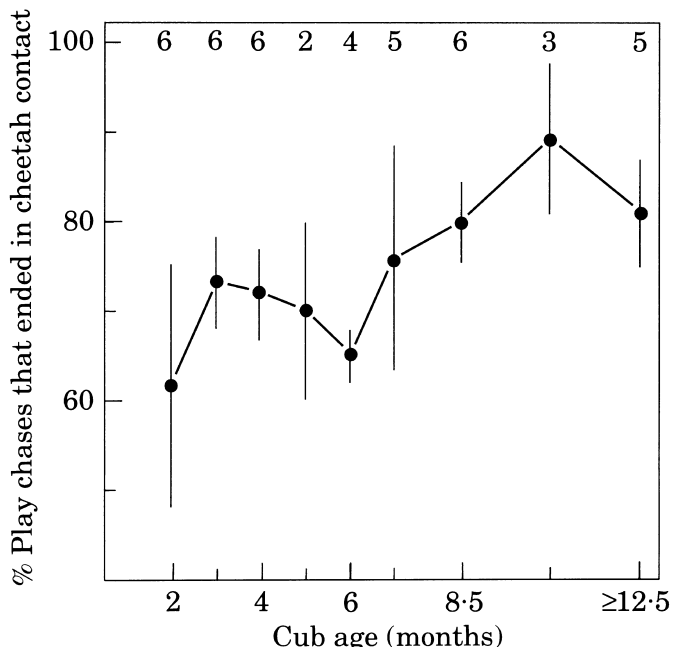

Figure 4. M ean $( \pm \mathrm{SE})$ percentage of play chases that resulted in cubs contacting (patting or grasping) either their mother or sibling plotted against cub age. N umber of litters are shown at the top.

chases mirrored the increasing distance that cubs chased prey as they grew older $(\bar{X}=23.3 \mathrm{~m}$, $\mathrm{SE}=5 \cdot 1, N=33$ litters, $r_{S}=0.540, P=0.001$ excluding litters in which only one chase occurred). Because opportunities for play were vastly greater than those for hunting prey, distances cubs chased each other in play most likely rehearsed the shortdistance sprints necessary to catch quarry rather than vice versa.

\section{$M$ easures of success in play}

The proportion of chases in which a cub contacted (i.e. patted or grasped) a family member at the end of a play chase rose with age $\left(r_{s}=0.307\right.$, $\mathrm{N}=43$ litters, $\mathrm{P}=0.023$ excluding litters in which only one chase occurred; Fig. 4). Similarly, the proportion of occasions that cubs contacted live prey after it had been released for them by their mothers increased slightly as cubs grew older ( $\bar{X}=88.8 \%$ success, $r_{S}=0.360, \quad N=16$ litters, $P=0.086)$ suggesting, perhaps, that contacting siblings at the end of play chases might have served as practice for contacting live prey. However, contacting cheetahs and live prey were not significantly correlated once the effect of age was removed (partial correlation coefficient controlling for cub age, $r=0.181, N=15$ litters, $P>0.2$ controlling for cub age). Finally, considering only
Table III. Summary of subtle changes in non-contact social play presented in the text

\begin{tabular}{lll}
\hline & \multicolumn{2}{c}{ Changes with age in relation to } \\
\cline { 2 - 3 } & \multicolumn{1}{c}{ Play } & \multicolumn{1}{c}{ Prey } \\
\hline $\begin{array}{c}\text { R emaining concealed } \\
\text { Stalking }\end{array}$ & No effect & No effect \\
$\begin{array}{c}\text { Crouching } \\
\text { Distances covered } \\
\text { R ushing around } \\
\text { Chasing }\end{array}$ & N o effect & Increases \\
$\begin{array}{c}\text { Success of chases } \\
\text { Contacting }\end{array}$ & Increases & In ot applicable \\
K nocks over & Increases & Increases \\
& D ecreases & Too infrequent \\
& & to measure \\
\hline
\end{tabular}

contacts made at the end of play chases, the percentage of occasions that a family target was knocked over after being patted or grasped by a youngster actually declined with cub age, presumably because cubs put more effort into getting away, and were better at keeping their balance $\left(r_{S}=-0.387, N=41\right.$ litters, $P=0.006$ excluding litters in which only one contact occurred). It seemed unlikely, therefore, that attempting to topple relatives in play provided helpful experience for bringing down prey, despite Prater's (1935) observations. These subtle aspects of play and hunting behaviour are summarized in Table III.

\section{DISCUSSION}

\section{The D evelopment of Play}

The average amount of time spent playing after emergence, $3.4 \%$ of the day, probably represented the average percentage of time spent playing during the whole period of dependence because, before 2 months of age, cubs had poorly developed motor skills and were probably asleep during much of their mother's long absences from the lair (K. Laurenson, personal communication). This figure is comparable to values from field studies of other carnivores, as well as ungulates and primates. F or example, Schaller (1972) found that three lion cub groups played for 1.5, 1.6 and $6.0 \%$ of the day, although their ages were not specified. M iller \& Byers (1991) showed that play represented $1-2 \%$ of the total time budget in 
pronghorn, Antilocapra americana, fawns. Freeliving primates play between 1 and $20 \%$ of the day (e.g. 3-14\% for red colobus, Colobus badius: Clutton-Brock 1974; 3 or $20 \%$ for olive baboons, Papio anubis: Rose 1977 and N ash 1978, respectively; 3-5\% for chacma baboons, $\mathrm{P}$ apio cynocephalus: Cheney 1978; and $1-6 \%$ for rhesus macaques, M acaca mulatta: Levy 1979) although these values are not necessarily comparable given widely divergent methods of data collection and calculation. Thus cheetahs did not play for an exceptionally greater percentage of time than other free-living species. Earlier reports of cheetahs' playfulness may have derived from cheetahs' conspicuousness in open areas and their diurnal habits.

Different types of cheetahs' play had distinct rates of development as reported for other species (domestic cats, Felis domesticus: Barrett \& Bateson 1978; olive baboons: Chalmers 1980; Cuvier's gazelles, Gazella cuvieri: G omendio 1988; south A merican fur seals, Arctocephalus australis; Harcourt 1991a). Different types of play may come under the influence of several different motivational systems as individuals mature (Caro 1981), and different components may serve different functions (Bateson 1981; Gomendio 1988). A Il these studies suggest that play is not a unitary category with regard to its development, causation or function (see also Pellis 1991).

In the past, locomotor play in juvenile mammals has been regarded as enhancing physical stamina and motor skills of adults (Bekoff $\&$ Byers 1981). If play has energetic or injury costs, however, selection ought to delay practising skills for adulthood until juveniles become stronger and less vulnerable. Therefore if we see play early in development it suggests either negligible costs or that play is needed to rehearse skills required during juvenile stages. In cheetahs, rates of Iocomotor play were highest between 2 and 4 months of age, at a time when predator-induced mortality is extremely high ( $L$ aurenson, in press). If locomotor play has immediate benefits by reducing the period of time that cubs are vulnerable to predators, this could explain why locomotor play occurs so early in development, even when cubs are temporarily jeopardized during locomotor performance (see below). This argument, based on design, suggests that locomotor play could be instrumental in developing an adequate flight response in juveniles and adds to a growing list of species in which a similar developmental pattern of play has been reported (bighorn lambs, 0 vis canadensis: Berger 1980; gazelle fawns: G omendio 1988; fur seal pups: H arcourt 1991a).

In cheetahs, object play developed more slowly than social play, similar to domestic kittens in which object play continues to rise after the seventh week of development, while cat contact and non-contact social play patterns such as rear and arch fall (Bateson \& Y oung 1981; but see also Caro 1981). In domestic cats, it has been argued that these different trajectories could be linked to kittens gaining social skills by playing with siblings in the nest, and then acquiring knowledge of their inanimate environment and prey through object play at a time when kittens are supposed to have left the nest (Bateson 1981). In cheetahs, however, these arguments are unlikely to apply because object play peaked 2 months after cubs had left their lair. In the intervening period, cubs had the opportunity to experience their immediate environment, had watched prey from afar, and had interacted with dead prey captured for them by their mothers. It therefore seems improbable that object play promoted acquisition of knowledge about their environment. More likely, increasing rates of exploratory behaviour seen during development enabled cubs to become better acquainted with their surroundings as they grew older.

\section{C osts of Play}

Typically, young cubs would be nursing at dawn when I found them (see also Laurenson 1993) but started contact play, either on top of, or within $1 \mathrm{~m}$ of their mother at around 0730 hours. The mother would rest until 0800 or 0815 hours and then move off, followed by her cubs, which might continue to play intermittently until 0900 hours, although this was highly variable. Y oung cubs sometimes also played between 1200 and 1300 hours and again between 1730 and 1900 hours while their mother was resting, suggesting that they too would have rested in the absence of play. A s play often started at the end of a bout of resting or suck ling, I suggest that young cubs were not deficient in either of these activities as a result of play. Offspring aged 5-7 months would ordinarily play in the mornings, and sometimes in the evenings, usually while the family was walking. $\mathrm{H}$ ere, moving was not displaced by play because 
cubs could keep up or even ahead of their mother through locomotor activity or non-contact social play. These arguments are speculative but they suggest that time costs of play may have been low.

Playing cubs suffered only minor damage to their feet or legs, which affected them for only a few minutes. Other field studies have demonstrated that play can result in a diverse set of injuries including falling (chimpanzees, $P$ an trogolodytes: van-Lawick Goodall 1968), being trapped in mud (elephants, Loxondata africana: D ouglas-H amilton \& D ouglas-H amilton 1975), being washed out to sea (Galapagos fur seals, A rctocephalus galapagoensis: A rnold \& Trillmich 1985), or being impaled on the spines of cacti (bighorn sheep: Berger 1980). N evertheless, the extent of such injuries during individual ontogenies and across these populations was not documented and these incidents might have been unusual, attracting observers' undue attention. It would be instructive to carry out systematic observations on juvenile ungulates in mountainous regions, and on arboreal primates because reports emphasize the special risks of falling in play (e.g. W elles \& W elles 1961; Budnitz \& D ainis 1975) but cheetahs were not subject to these risks most of the time.

Play may have made cubs more conspicuous to predators since it attracted my attention. U nfortunately, it was very difficult to determine the exact moment predators saw a cheetah family, since I was near the latter. Therefore, I could not test whether play specifically attracted predators' attention. $\mathrm{N}$ evertheless, mothers showed little evidence of unease while their cubs were playing, suggesting it did not increase risk of predation unduly.

In a recent study, Harcourt (1991b) showed that animals were at risk to predators because play distracted them. He saw 26 south A merican fur seal pups caught and killed by southern sea lions, 0 taria bryonia, in the wild, 22 of which were playing at the time they were captured. Because pups played for only $6 \cdot 1 \%$ of the time, survivorship costs of play were extremely high in this species. $\mathrm{H}$ arcourt interpreted the high mortality as resulting from pups being distracted during play and failing to join the flight of non-playing conspecifics, rather than play attracting attention as posed for cheetahs. Distraction was unlikely to be an important consequence of play in cheetahs because a cub's primary defence against predators was its mother, which was always close by during play.

Energy costs of play were not assessed in this study but energy expended during play has been estimated for other species. Play in freeliving pronghorn fawns took up $3 \%$ of total daily energy expenditure excluding growth, and $20 \%$ of energy expenditure in excess of resting metabolism and growth (M iller \& Byers 1991). In 10-week-old laboratory reared domestic kittens, M artin (1984) found that the energetic costs of play accounted for $4-9 \%$ of total daily energy expenditure, excluding growth. Similarly, Siviy \& A trens (1992) found that play in domestic rats, Rattus norvegicus, accounted for $2-3 \%$ of the total energy budget, assuming a juvenile spends $3 \%$ of the day playing. As cheetah cubs spent less time playing than kittens and an equivalent time to rat pups, it is reasonable to argue that play in cheetahs accounted for an absolute maximum of between 5 and $10 \%$ of total daily energy expenditure even in young cubs where non-contact and locomotor play were at their zenith.

A $10 \%$ loss in energy expenditure would reduce tissue growth in the short term (M iller \& Byers 1991) but this might not affect juvenile survival unduly because predation was the principal cause of mortality in cheetah cubs (L aurenson, in press). Moreover, a $10 \%$ loss of energy for a healthy individual may be small compared with a $30 \%$ average of total metabolizable energy intake used in growth ( $M$ artin 1984); consequently, energy costs of play in healthy cheetahs may not have been overly large. In sick cubs, however, a 10\% loss was probably substantial: an ill 8-month-old female cub showed no signs of play at all during the four mornings and evenings before dying.

Before concluding that the costs of play to cheetah cubs are trivial, effects of play on other indispensible family members need be considered (Caro 1987b). The most obvious indirect effect of cub play was on maternal hunting success. Out of 653 mothers' hunts that I saw, 478 failed. Seven of these failures $(1.5 \%)$ were unequivocally due to prey being alerted by seeing the cubs play ( $\mathrm{C}$ aro 1987b). For example, young cubs sometimes clambered over their mother when she crouched or sat up to look at prey between bouts of stalking, and older cubs went on chasing each other after their mother had commenced her stalk. As cubs caused a minimum of 78 hunts to fail, play per se accounted for $9.0 \%$ of these failures. 
Table IV. A pproximate magnitude of all the costs of play in cheetah cubs

\begin{tabular}{ll}
\hline \multicolumn{1}{c}{ Type of cost } & Size of cost \\
\hline $\begin{array}{l}\text { O pportunity costs } \\
\text { Survivorship costs } \\
\text { Injury costs }\end{array}$ & L ow \\
R isk of separation & Very low \\
Predation costs & Very low \\
M aternal responses to & U nknown \\
potential predation risk & A ct as if low \\
Energy costs & Possibly low \\
Indirect costs & Probably low \\
\hline
\end{tabular}

Focusing on this $9.0 \%$ figure, I previously argued that play had a relatively large impact on maternal hunting success (Caro 1987b). Compared with the total number of hunts, however, the indirect effect was less pronounced: only seven out of 653 hunts $(1 \cdot 1 \%)$ failed as result of cub play and some of these hunting episodes might have subsequently failed for other reasons had they not been disrupted by play, as pointed out earlier (Caro 1987b). W hereas the necessity of having to consider indirect costs is not diminished by this reappraisal, it may be most cautious to argue that indirect effects of play are small in free-living cheetahs. In summary, the overall costs of play in cheetahs appeared low (Table IV) implying that its benefits need not have necessarily been large to have been favoured by natural selection.

\section{A ssociations between $\mathrm{P}$ lay and $\mathrm{P}$ redatory Behaviour}

Stalking and crouching in non-contact social play were associated with the same behaviour patterns when cubs attempted to hunt prey, and object play and contact social play were associated with contacting live prey released by mothers. These findings raise three issues. First, litter-mates that often stalked and crouched at prey may have been better able to do so as a result of this type of play, or vice versa. However, it is less likely that predation attempts served as practice for play because bouts of object and particularly contact play were far more frequent than predatory attempts (C aro 1994). Second, patterns of stalking and crouching in play may have been influenced by the same causal factors that affected these patterns during hunts. Third, play stalks
T able V. Possible short-term benefits of different categories of play in cheetah cubs

\begin{tabular}{ll}
\hline \multicolumn{1}{c}{ Categories of play } & \multicolumn{1}{c}{ Function } \\
\hline Object play & Contacting live prey \\
Contact social play & Contacting live prey \\
N on-contact social play & A pproaching prey \\
L ocomotor play & Escaping predators
\end{tabular}

and crouches may both have been related to an unidentified third variable (other than age) that was not measured. At present, these possibilities cannot be distinguished. Object and contact social play in domestic cats are also associated with predation in this fashion (Caro 1981) indicating that these forms of cat play may serve as practice for contacting live prey but, again, common causal factors cannot be excluded.

Distances covered in play chases and cubs' ability to contact their targets were respectively associated with length of chases and success in contacting prey during ontogeny. This suggested that play chases may have been functionally or causally related to chases in hunting. However, there seemed to be little relationship between remaining concealed in non-contact social play and remaining concealed during hunting. Lack of age-related changes in the distance cubs rushed around in play is again consistent with locomotor play being unrelated to hunting.

In conclusion, the findings of this study are as follows. (1) Object play and contact social play, in particular contact made at the end of play chases, were associated with contacting live prey (Table V). (2) R ates of non-contact social play (crouching and stalking) were related to rates of approaching prey; however, lack of correspondence between staying concealed during play and during hunts suggested play had little effect on perfecting cheetahs' ability to remain concealed during hunts. (In general, non-contact social play was not associated with prey contact.) (3) The design features of locomotor play suggest that it may serve as practice for escaping predators. M oreover, neither locomotor play, nor one of its constituents, rushing around, was related to hunting. These results support the idea that separate aspects of play share common causal influences with different activities that have known functions, but the possibility that different 
categories of play actually serve as practice for different forms of 'serious behaviour' is more tenuous.

A rguments concerning the function of behaviour based on its structural design or on correlations are weak because they do not show that play actually does affect 'serious' behaviour. $Y$ et if relied upon as a last resort, fine-grained analyses make such arguments more sophisticated (for example, analyses of play in rats; Hole 1988). In cheetahs, changes in the structural properties of play reflect specific aspects of hunting behaviour in cubs. $\mathrm{N}$ evertheless, experiments are needed to determine whether play affects the kinds of behaviour uncovered by these correlations, both in the short term and in adulthood.

\section{ACKNOWLE DG M E TS}

I thank the Government of Tanzania, Tanzania $N$ ational Parks and the Serengeti Wildlife Research Institute for permissions, the Royal Society, U.K. for funding, and Pat Bateson, Monique Borgerhoff Mulder, John Byers and W arren $\mathrm{H}$ olmes for comments on the manuscript.

\section{REFERE NCES}

A bbey, H.\& H oward, E. 1973. Statistical procedure in developmental studies on species with multiple offspring. D evl Psychobiol., 6, 329-335.

Adamson, J. 1969. The Spotted Sphinx. London: Collins.

A rnold, W. \& Trillmich, F. 1985. Time budget in $G$ alapagos fur seal pups: the influence of the mother's presence and absence on pup activity and play. B ehaviour, 92, 302-321.

Barber, N. 1991. Play and energy regulation in mammals. Q. Rev. Biol., 66, 129-147.

Barrett, P. \& Bateson, P. 1978. The development of play in cats. B ehaviour, 66, 106-120.

Bateson, P. 1981. Discontinuities in development and changes in the social organization of play in cats. In: Behavioural Development ( $\mathrm{Ed}$. by $\mathrm{K}$. Immelmann, G. W. Barlow, L. Petrinovich \& M. M ain), pp. 281-295. Cambridge: Cambridge U niversity Press.

Bateson, P. \& Y oung, M. 1981. Separation from the mother and the development of play in cats. Anim. Behav., 29, 173-180.

Bekoff, M. 1989. Behavioral development of terrestrial carnivores. In: Carnivore Behavior, Ecology and Evolution ( $\mathrm{Ed}$. by J. L. Gittleman), pp. 89-124. N ew Y ork: Cornell U niversity Press.

Bekoff, M.\& Byers, J. A. 1981. A critical reanalysis of the ontogeny and phylogeny of mammalian social and locomotor play: an ethological hornet's nest. In: Behavioural Development ( $\mathrm{Ed}$. by $\mathrm{K}$. Immelmann, G. W. Barlow, L. Petrinovich \& M. Main), pp 296-337. Cambridge: Cambridge U niversity Press.

Bekoff, M . \& Byers, J. A . 1992. Time, energy and play. A nim. Behav., 44, 981-982.

Berger, J. 1980. The ecology, structure and functions of social play in bighorn sheep (Ovis canadensis). J. Z ool., L ond., 192, 531-542.

Bertram, B. C. R. 1978. Pride of Lions. L ondon: Dent.

Budnitz, N. \& Dainis, K. 1975. Lemur catta: ecology and behavior. In: L emur Biology ( $\mathrm{Ed}$. by I. Tattersall $\&$ R. W. Sussmann), pp. 219-235. N ew Y ork: Plenum Press.

Caro, T. M . 1981. Predatory behaviour and social play in kittens. Behaviour, 76, 1-24.

Caro, T. M. 1987a. Cheetah mothers' vigilance: looking out for prey or for predators? B ehav. E col. Sociobiol., 20, 351-61.

Caro, T. M . 1987b. Indirect costs of play: cheetah cubs reduce maternal hunting success. Anim. Behav., 35, 295-97.

Caro, T. M . 1988. A daptive significance of play: are we getting closer? Trends E col. Evol., 3, 50-54.

Caro, T. M. 1990. Cheetahs' mothers bias parental investment in favour of cooperating sons. E thol. E col. Evol., 2, 381-395.

Caro, T. M. 1994. Cheetahs of the Serengeti Plains: Group L iving in an A social Species. Chicago: U niversity of Chicago Press.

Caro, T. M . \& H auser, M. D. 1992. Is there teaching in nonhuman animals? Q. R ev. Biol., 67, 151-174.

Chalmers, N. R. 1980. The ontogeny of play in feral olive baboons (Papio anubis). Anim. Behav., 28, 570-585.

Chalmers, N . R . \& L ocke-H aydon, J. 1984. Correlations among measures of playfulness and skillfulness in captive common marmosets (Callithrix jacchus jacchus). D evl P sychobiol., 17, 191-208.

Cheney, D. L. 1978. The play partners of immature baboons. A nim. Behav., 26, 1038-1050.

Clutton-Brock, T. H. 1974. A ctivity patterns of red colobus (C olobus badius tephrosceles). Folia primatol. 21, 161-187.

Douglas-H amilton, I. \& D ouglas-H amilton, O. 1975 A mong the Elephants. N ew Y ork: Viking.

Estes, R. D. 1991. The Behavior Guide to A frican M ammals. Berkeley: U niversity of California Press.

Fagen, R. 1981. A nimal Play Behavior. N ew Y ork: Oxford U niversity Press.

Frame, G. W . \& Frame, L. H. 1980. Cheetahs: in a race for survival. Nat. Geogr., 157, 712-728.

Frame, G . W . \& F rame, L. H . 1981. Swift and Enduring: Cheetah and W ild Dogs of the Serengeti. N ew Y ork: E. P. D utton.

G omendio, M . 1988. The development of different types of play in gazelles: implications for the nature and functions of play. A nim. Behav., 36, 825-836.

$\mathrm{H}$ arcourt, R. 1991a. The development of play in the South A merican fur seal. E thology, 88, 191-202.

H arcourt, R. 1991b. Survivorship costs of play in the South A merican fur seal. A nim. B ehav., 42, 509-511. 
Hole, G. 1988. Temporal features of social play in the laboratory rat. E thology, 78, 1-20.

L aurenson, M . K . 1993. Early maternal behavior of wild cheetahs: implications for captive husbandry. Z00 Biol., 12, 31-43.

Laurenson, M. K. In press. $\mathrm{H}$ igh juvenile mortality in cheetahs and its consequences for maternal care. J. Z ool., L ond.

van-L awick Goodall, J. 1968. The behaviour of free living chimpanzees in the Gombe Stream Reserve. A nim. B ehav. M onogr., 1, 161-311.

Levy, J. 1979. Play behavior and its decline during development in rhesus monkeys (M acaca mulatta). Ph.D. thesis, U niversity of Chicago.

$M$ artin, P. 1984. The time and energy costs of play behaviour in the cat. Z. Tierpsychol., 64, 298-312.

$M$ artin, P. \& Bateson, P. 1986. M easuring Behaviour. Cambridge: Cambridge U niversity Press.

M artin, P. \& Caro, T. M . 1985. On the functions of play and its role in behavioural development. Adv. Study Behav., 15, 9-103.

M iller, M. N.\& Byers, J. A. 1991. Energetic costs of locomotor play in pronghorn fawns. A nim. B ehav., 41, 1007-1013.

M uller-Schwarze, D. 1984. A nalysis of play behaviour: what do we measure and when. In: Play in A nimals and $\mathrm{H}$ umans (Ed. by P. K. Smith), pp. 147-158. Oxford: Blackwell Scientific Publications.

$\mathrm{N}$ ash, L. T. 1978. The development of the mother-infant relationship in wild baboons (Papio anubis). Anim. Behav., 26, 746-759.
Packer, C. 1986. The ecology of sociality in felids. In: Ecological Aspects of Social Evolution: Birds and M ammals (Ed. by D. I. Rubenstein \& R. W. W rangham), pp. 429-451. Princeton, $\mathrm{N}$ ew Jersey: Princeton U niversity Press.

Pellis, S. M . 1991. H ow motivationally distinct is play? a preliminary case study. A nim. Behav., 42, 851-853.

Prater, S. H. 1935. The wild animals of the Indian empire. III. Carnivora or beasts of prey. J. Bombay nat. $\mathrm{H}$ ist. Soc., 37, 112-166.

R ose, M . D. 1977. Positional behavior of olive baboons ( $P$ apio anubis) and its relationship to maintenance and social activities. Primates, 18, 59-116.

Schaller, G. B. 1972. The Serengeti Lion: A Study of Predator-Prey Relations. Chicago: University of Chicago Press.

Siviy, S. M . \& A trens, D. M . 1992. The energetic costs of rough-and-tumble play in the juvenile rat. Devl P sychobiol., 25, 137-148.

Smith, P. K. 1982. Does play matter? F unctional and evolutionary aspects of animal and human play. B ehav. Brain Sci., 5, 139-184.

Smith, P. K . \& Simon, T. 1984. Object play, problemsolving and creativity in children. In: Play in A nimals and $\mathrm{H}$ umans (Ed. by P. K. Smith), pp. 199-216. Oxford: Blackwell Scientific Publications.

W elles, R. E. \& W elles, F. B. 1961. The Bighorn of D eath Valley, Fauna of the $N$ ational Parks of the $U$ nited States. Fauna Series N 0. 6. Washington D.C.: U.S. Government printing office. 